\title{
Mountain Area Based on MIDAS/GTS Model Earthwork Excavation Slope Stability Analysis
}

\author{
Zhang Baoliang ${ }^{1, a}$, Li Dahua ${ }^{1, b}$, Shao Xianfeng ${ }^{2, c}$ \\ 1.School of Civil Engineering, Anhui jianzhu University,230601,Heifei,China \\ 2.State Grid Anhui Economic Research Institute \\ a1169273902@qq.com; bLdh2006a@163.com; cxianfengyihao83@163.com
}

\begin{abstract}
Keywords: slope stability; MIDAS/GTS; Simulation analysis; Monitoring value
Abstract: For research on slope stability in the mountain areas of South Anhui special complex condition, the State Grid Xuancheng Guquan $+1100 \mathrm{kw}$ converter of embankment slope construction as the engineering background, the stability of slope is simulated by MIDAS/GTS software, and the actual monitoring data are analyzed; at the same time analysis of slope support before and after supporting the simulation, verification of MIDAS/GTS in analysis of slope stability and applicability, effect of retaining structure on the slope strength.
\end{abstract}

\section{Introduction}

The design of the slope in slope stability analysis, on the basis of determining the slope destruction form, select the appropriate slope and retaining scheme ${ }^{[1]}$. When was the slope stability analysis, determines the slope instability and the decline of power, to offer a scientific basis for slope retaining ${ }^{[2,3]}$. With the development of the computer, through a variety of software on the slope stability analysis, bring us very big harvest $\left.{ }^{[4}\right]$. At present, the commonly used three ${ }^{[5-11]}$. slope stability analysis software ANSYS, FLAC3D, the MIDAS/GTS, scaled ${ }^{[12]}$ adina.the. MIDAS/GTS (Geotechnical and Tunnel analysis System) is a general finite element analysis of the kernel and the organic integration of professional requirements of rock and soil structure and development of rock and soil and Tunnel structure finite element analysis software, the software interface is simple and powerful functions before and after processing, suitable for most forms of rock mass damage ${ }^{[13,14] \text {. }}$

\section{Project Overview}

$+1100 \mathrm{kv}$ ZhunDong (changji) - (search) uhv dc project in southern anhui province is currently the highest voltage class and transmission capacity of the largest in the world, transmission distance, as far as the most advanced technological level of uhv dc transmission project, is uhv dc transmission technology innovation and development of a new peak. According to the preliminary estimate the project excavation volume of about 1.3 million cubic meters, fill the amount of about 1.28 million cubic meters, involving the earth quantity greatly. For low tectonic denudation QiuGangDe engineering features, overall terrain tilt from west to east, reduced. Hills, downland slope is extremely slow, grade $7^{\circ}$ and $25^{\circ}$; Ground surface elevation Construction site is high in central, south, north side is low, in northeast, the lowest for artificial ponds. Outside the site excavation slope is located in the west, the southwest side of the station and the Middle East, total length of $1109.6 \mathrm{~m}$, the highest is about $13.6 \mathrm{~m}$; This overlay area peripheral excavation slope length is 341.1 $\mathrm{m}, 14.6 \mathrm{~m}$. The overall design is put POE + soil nailing + NF Gao Jiangzhi carpet surface protection, NF Gao Jiangzhi base blanket with soil nailing fixation, put the slope ratio of 1:1. 25, every $8.0 \mathrm{~m}$ high slope set a width of $2.0 \mathrm{~m}$.. Mountain in southern anhui province geology is complicated, the selected slope geological conditions from the surface of the pebble, silty clay, clay, silty clay, argillaceous siltstone. Construction of xuancheng region during the rainy season, according to the usual weather statistics, June and July are divided into the local rainy season, the whole construction period in rainy day and sunny day. In this paper, using MIDAS/GTS software simulation, SRM method was applied to make the Mohr - coulomb failure criteria, the reduction of 
soil C, phi, until no convergence, the use of SRM method of stability analysis for each construction stage.

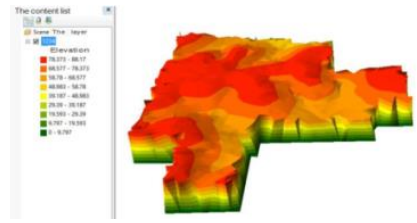

Figure 1 field three-dimensional topographic map

\section{Slope Stability Analysis Method}

\subsection{Engineering on the limit equilibrium method (LEM)}

Limit equilibrium method[15] (LEM; limit equilibrium method) has some advantages such as simple model, the formula is simple, easy to understand, and designers are often used to engineering practice in safety (safety factor) or limit load designed to determine the stability of the construction of the project, so the method has been widely applied, and is the current specification by writing the code for building slope engineering technology.

Limit equilibrium method, the difficulty lies in the potential of the most dangerous sliding surface search and determination of the slope stability safety factor. Limit equilibrium method using some simplified assumptions on mechanics, didn't meet the yield criterion and associated flow rule, so the result is not real answer system. According to the concept of limit analysis, the solution obtained by the limit equilibrium method is neither nor lower limit solutions, so still need to improve.

\section{2 on the mechanics of the limit analysis method (LAM)}

Lysmer (1) the limit analysis method on the mechanics (LAM: limitanalysis method) in soil mechanics. Limit analysis method has a more rigorous theoretical basis, the failure surface and the stress distribution on the do not prior assumptions, can provide users with a clear failure mode etc. But due to the heterogeneity of rock and soil materials, anisotropy and nonlinear constitutive relation and the yield criterion and its body swelling, softening, large deformation and other characteristics, make practical solving geotechnical slope stability problem becomes very difficult and complicated, fully meet the static equation, motion equation and corresponding boundary Boundary conditions of solutions is almost impossible.

\section{3 math of slip line field method (SLM)}

Slip line field method (SLM; slip - lines field method) including the Sokolovakii the statics theory and Hansen, put forward the kinematics theory, put forward by considering the limit equilibrium equation for a group of the elliptic differential equations, using the stress characteristic line and speed characteristic line and its boundary conditions, the geometry characteristic of the resulting from the lower limit is set up on mathematics method and the limit method. This method in the foundation bearing capacity, earth pressure retaining wall and slope stability problems in some applications, but because of its difficult, mathematics to solve practical application is limited.

\section{4 finite element method (FEM)}

Finite element slope stability analysis usually includes finite element arc search method and strength reduction finite element method (fem) method. In finite element method of circular arc search ${ }^{[16]}$, each node is obtained by finite element analysis of the stress tensor, and assume a sliding 
surface and sliding surface is given by finite element data of normal stress and shear stress. According to the Mohr - Coulomb failure criteria can calculate anti-sliding force of this point. The sliding surface can be obtained the slide in each node force and anti-sliding force, again to slide on the surface of the sliding force and integral sliding resistance and the coefficient of each stable sliding surface can be obtained. That assume a circular arc sliding surface, and changing the center of a circle with radius to search, can get minimum slope stability coefficient, the slope stability safety coefficient. In finite element strength subtraction, through constant lower intensity, the finite element calculation, until the system reaches instability state, on the basis of finite element calculation convergence, not exceed a certain generalized shear strain amplitude or equivalent plastic strain belt and within the plastic zone of slope, the node node displacement mutation or strength reduction factor and peak horizontal displacement curve slope reaches a fixed value method to determine the critical instability state of the slope and its stability safety factor. Its main advantage is compared with the limit equilibrium method, without prior assumption that the shape and position of sliding surface; Don't need to size and direction of the force between soil hypothesis [17]. Can consider analysis domain of complex shape and boundary condition, the physical nonlinearity of material and geometrical nonlinearity, to consider a variety of rock and soil mass constitutive relation of stress and deformation, the influence of to simulate instability process and slip plane of slope shape, can analyze the deformation failure mechanism of slope, the most prone to yield failure parts and needs first to reinforce areas, etc.; When calculating the factor of safety, do not need to assume that the sliding surface shape in advance, thus obtained the widespread attention recently.

\section{The Establishment Of The Model}

According to the practical slope using AutoCAD 2014 - Simplified Chinese (Simplified Chinese) to establish a two-dimensional model of slope, the slope model section size is 70 m (length) x $30 \mathrm{~m}$ (high), the high slope of $19 \mathrm{~m}$, according to 1:1. 25 slope. Geology of pebble (Micronesia) respectively, silty clay (plastic) (plastic), silty clay, clay (hard plastic), argillaceous siltstone (strong weathering), slope model is shown in figure 2. This paper xuancheng search mountain geological constitutive model, the modified Mohr - coulomb model obedience under the plane strain of modified Mohr - coulomb criterion, the stability analysis using the finite element method of strength subtraction, table 1 for the soil physical and mechanical performance parameters.

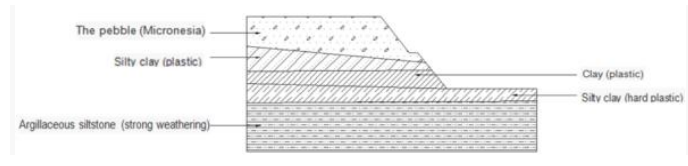

Figure 2 a two-dimensional model of the slope

Table 1 Physical and mechanical parameters of soil

\begin{tabular}{lccll}
\hline the soil category & $\begin{array}{c}\text { Severe/ } \\
(\mathrm{KN} / \mathrm{m} 3)\end{array}$ & $\begin{array}{c}\text { cohesive force/ } \\
(\mathrm{K} \mathrm{Pa})\end{array}$ & $\begin{array}{l}\text { angel } \\
\text { internal/ }(\circ)\end{array}$ & $\begin{array}{l}\text { of } \\
\end{array}$ \\
& & $\begin{array}{l}\text { The } \\
\text { compression } \\
\text { modulus/ }(\mathrm{M} \\
\mathrm{Pa})\end{array}$ \\
\hline
\end{tabular}




\begin{tabular}{|c|c|c|c|c|c|}
\hline $\begin{array}{l}\text { The pebble } \\
\text { (Micronesia) }\end{array}$ & 20.5 & 11 & 40.0 & - & 0.20 \\
\hline $\begin{array}{l}\text { Silty clay } \\
\text { (plastiy) }\end{array}$ & 19.6 & 29 & 16.7 & 8.2 & 0.25 \\
\hline clay (plastic) & 18.8 & 41 & 13.4 & 8.0 & 0.35 \\
\hline $\begin{array}{l}\text { Silty clay } \\
\text { (hard plastiy) }\end{array}$ & 19.5 & 45 & 17.7 & 13.9 & 0.25 \\
\hline $\begin{array}{l}\text { argillaceous } \\
\text { siltston(strong } \\
\text { weathering) }\end{array}$ & 21 & 11 & - & 16.0 & 0.24 \\
\hline
\end{tabular}

The built model is saved as a DWG format, and through the import of MIDAS/GTS NX software function the two-dimensional slope model import, and then for meshing. Meshing order from clay layer, in turn toward both sides, including clay layer seed size is 1 , silty clay plant size is 1.5 , the pebble layer and argillaceous siltstone seed size is 2 , division of slope model is shown in figure 3 .

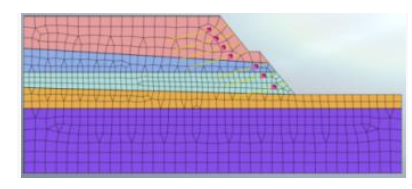

Figure 3 meshing

\section{Slope Calculation Result Analysis}

\subsection{Theoretical basis}

Slope stability analysis of this paper is based on the MIDAS/GTS strength reduction theory, under the theoretical basis of coefficient of finite element strength subtraction is the basic principle of the slope body strength parameters (cohesive force and Angle of internal friction values) and divided by a reduction factor Fs, get a new set of values, and then as a new material parameters input, then the trial, use the corresponding stability criteria, determine the corresponding Fs value of the minimum safety factor of slope, the slope reaches limit state, shear failure occurs, and the destruction of the slope sliding surface can be obtained at the same time. Strength reduction equations as follows (1) (2) (3).

$$
\begin{aligned}
C_{F} & =C / F_{S} \\
\phi_{F} & =\tan ^{-1}\left(\tan \phi / F_{S}\right) \\
\tau_{f F} & =C_{F}+\sigma \tan \phi_{F}
\end{aligned}
$$

After $\mathrm{CF}$ for the reduction of soil cohesive force, $\mathrm{C}$ as the cohesive force of soil, the Fs for strength reduction factor, $\phi \mathrm{F}$ after reduction internal friction Angle of soil, $\phi$ internal friction Angle of soil, $\tau \mathrm{fF}$ for reduction of soil shear strength.

\section{2 the slope analysis}

First analysis the original slope, that is, only consider the foundation support and under the condition of gravity, using MIDAS/GTS to simulate a slope, it is concluded that the stability of the slope coefficient is 1.34 , between $1.30 \sim 1.50$, basic can achieve the geotechnical engineering specification limit (GB50021-2001) regulation, slope is in steady state, can meet the requirements of the slope stability. The original slope displacement nephogram as shown in figure 4. 


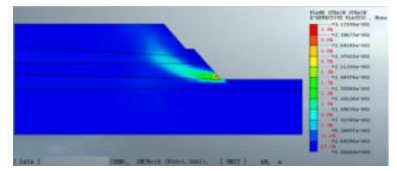

Figure 4 original slope deformation nephogram

Slope construction period in rainy season in southern anhui province, considering the stability of the slope under the heavy rain conditions conducive to defense measures to prevent the slope instability in advance, prepare for safe construction. This year xuancheng search encounters rainstorm, rainfall of $200 \mathrm{~mm}$ and above. Considering the heavy rainfall conditions, the use of MIDAS/GTS simulation analysis was carried out on the slope stability, finally it is concluded that the slope in the rainwater seepage stability safety coefficient is 1.004 , in the cases of < journal of geotechnical engineering standard gauge (GB50021-2001) regulation of the range of $1.30 \sim 1.50$, the slope is in unstable state. Rainfall conditions of slope displacement nephogram as shown in figure 5, shear stress nephogram of slope is shown in figure 6.

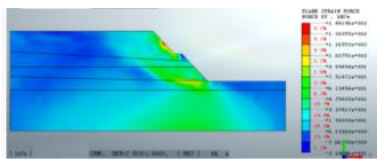

Figure 5 plane stress nephogram

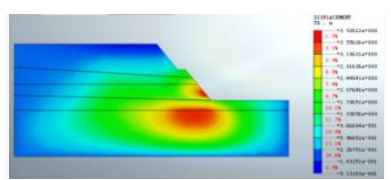

Figure 6 The shear stress distribution nephogram of slope

Slope under heavy rain conditions in a state of flux, so you need to take reinforcement measures, put slope reinforcement measures taken + soil nailing + NF Gao Jiangzhi carpet surface protection, NF Gao Jiangzhi base blanket with soil nailing fixation, soil nailing using $\Phi 20$ grade hrb335 reinforced, and the horizontal Angle $>15^{\circ}$ Angle into the slope, the distance of $2.5 \mathrm{~m}$ (horizontal) $\mathrm{x}$ $2.5 \mathrm{~m}$ (vertical direction). After soil nail reinforcement with MIDAS/GTS slope stability analysis of slope, the stability safety coefficient is 1.41 , can meet the specification limits. X axis displacement are shown in figure 7.

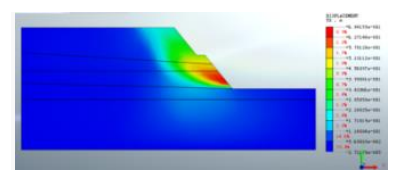

Figure $7 \mathrm{X}$ direction displacement nephogram

\section{Monitoring Value And Simulation Value Of Comparative Analysis}

Using LEICA total station combined with Quikslpoe software, on the slope monitoring, Quikslpoe software to monitor the data into chart, very image shows that the displacement of monitoring 
points and the change rule. Monitoring to the slope displacement results with MIDAS/GTS simulation results, this paper compares and analyzes the monitoring point arrangement on the slope at all levels, each level of not less than five monitoring points, monitoring stations spacing of 15 $30 \mathrm{~m}$, the possible formation of sliding zone, place monitoring key encryption points, the MIDAS/GTS model to extract the corresponding monitoring position as shown in figure 8 .

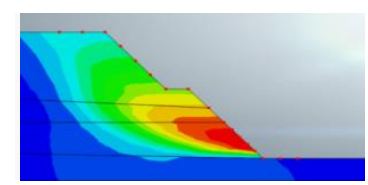

Figure 8 monitoring location

Before starting the monitoring, measured with total station of each measuring point again and again many times, after the numerical stability and average as the initial coordinate values, after each time measurement used in the total station to measure the real-time coordinate of observation points recorded in special observation in the table, compared with the initial coordinate, compute the cumulative displacement. Twice before and after the difference between the cumulative displacement, a quick twice before and after displacement. To slope monitoring value and simulation value of $\mathrm{X}$ to, for example, on the slope were analyzed, the results are shown in figure 9.

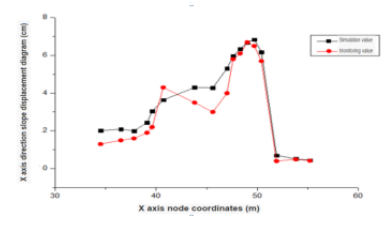

Figure $9 \mathrm{X}$ direction of slope monitoring value and analog value

The figure 9 shows that the slope displacement in $\mathrm{X}$ direction maximum slope toe, and monitoring value and simulation value of MIDAS/GTS present a high degree of consistency.

\section{The Conclusion}

1) through the use of MIDAS/GTS for simulating complex geological condition of slope, and it is concluded that the original slope stability coefficient is 1.34 , in a stable state. On heavy rain conditions, the slope stability safety coefficient is 1.004 , a sharp drop in slope stability.

2) after put POE + soil nailing + NF Gao Jiangzhi base after reinforcement carpet surface protection of slope stability safety coefficient is 1.41 , dramatically improve the stability of the slope, verify the validity of the reinforcement measures and its value in slope reinforcement.

3) specifies the real-time monitoring of slope, and the monitoring results and MIDAS/GTS simulation results were analyzed, through the real-time monitoring results and MIDAS/GTS simulation results highly consistency, fully embodies the MIDAS/GTS practicability and validity in slope stability analysis, is worth promoting.

\section{Acknowledgement}

Item number: (1P12001500010681000000)

Unit name: State Grid Anhui Economic Research Institute

Project name: The research and application of key technology-extra large-scale earthwork for $\pm 1100 \mathrm{kV}$ UHV DC converter station. 


\section{References}

[1] handsome hongyan, wen-xi han Zhao Jin dry. Midas/GTS software application in the three-dimensional slope stability analysis [J]. Journal of geological hazards and environmental protection, 2009 01:104-107.

[2] Gu Xiaojiang. The slope stability analysis method and its application [D]. Shanghai jiaotong university, 2007.

[3] Luo Zhengdong. The slope stability analysis based on the theory of the inverse reliability method research [D]. Hunan university, 2014.

[4] lesser, zhi-qiang zeng, shu-lin pan. Slope stability analysis method of review [J]. Journal of xihua university (natural science edition), 2012, 11:101-105.

[5] HUNGR o. An extension of Bishop's simplified method of slope stability analysis to three dimension [J]. Geotechnique, 1987, 37 (1) : 113-117.

[6] HUANG, c. c. TSAI, c. c. New method for $3 \mathrm{~d}$ and asymmetrical slope stability analysis [J]. Journal of Geotechnical and Environmental Engineering, 2000, 126 (10) : 917-927.

[7] CHEN R H, Chameau J L. Three - dimensional limit equilibrium analysis of slopes [J]. Geotechnique, 1982, 32 (3) : 31-40.

[8] HUTCHINSON J N, SARMA s. k. Discussion on three - dimensional limit equilibrium analysis of slopes [J]. Geotechnique, 1985, 35 (6) : 215-216.

[9] LAM, L FREDLUND D g. A general limit equilibrium model for three - dimensional slope stability analysis [J]. Canadian Geotechnical Journal, 1993, 30 (4) : 905-9 19.

[10] CHEN Zu - yu, WANG Xiao gang, HAHERFIELD C, et al. A three - dimensional slope stability method using the upper bound, unseen, part I going and the methods [J]. International Journal of Rock Mechanics and Mining, Sciences, 2001, 38 (2) : 369-378.

[11] CHEN Zu - yu, WANG Jian, WANG yu jie, et a1. A three - dimensional slope stability method using the upper bound, unseen, part II: numerical apprnaches [J]. International Journal of Rock Mechanics and Mining, Sciences, 2001, 38 (2) : 379-397.

[12] xiao-qiang hou, Tian Shutao. Based on Midas/GTS high slope excavation and reinforcement construction stability analysis [J]. Journal of subgrade engineering, 2013, and practices: +186 178-181.

[13] Gu Xiaojiang. The slope stability analysis method and its application [D]. Shanghai jiaotong university, 2007.

[14], peng Liu Guoyu, wei-ping tian. The slope stability analysis of limit equilibrium method and strength subtraction comparative study (II) [J]. Transportation standardization, 2011, Z1:33-36.

[15] guo-qing Chen, Dr. Huang, yu-chuan shi, be strong. Based on dynamic and overall strength subtraction of slope stability analysis [J]. Journal of rock mechanics and engineering, 2014, 11:243-256.

[16] zong-ze Yin lu qing feng. Circular sliding finite element slope stability analysis [J]. Rock and soil mechanics, 2005, 26 (10) : 1525-1530.

[17] Jiang Xin yan-jun qiu, jian-ming ling. Strength subtraction software on the evaluation of slope stability of [J]. Journal of underground space and engineering, 2008, 11:302-309. 